\section{BelMiDak-Rust-Resistant Navy Dry Beans Germplasm Lines}

J.R. Stavely ${ }^{1}$

Molecular Plant Pathology Laboratory, U.S. Department of Agriculture, Agricultural Research Service, Beltsville, MD 20705-2350

J.D. Kelly ${ }^{2}$

Crop and Soil Sciences Department, Michigan State University, East Lansing, MI 48824

\section{K.F. Grafton ${ }^{2}$}

Department of Crop and Weed Sciences, North Dakota State University, Fargo, ND 58105

Additional index words. Phaseolus vulgaris, Uromyces appendiculatus var. appendiculatus, bean common mosaic virus, disease resistance
BelMiDak-Rust-Resistant (RR) -1,-2,-3, $-4,-5,-6,-7,-8$, and -9 are the first rustresistant navy dry bean (Phaseolus vulgaris L.) germplasm lines that are homozygous for resistance to all 65 available races of the bean rust pathogen, Uromyces appendiculatus (Pers.)Unger var. appendiculatus [U.phaseoli (Reben) Wint.]. BelMiDak-RR-1 through -9 derived comprehensive rust resistance from U.S. Dept. of Agriculture plant introduction (PI) 181996

All nine BelMiDak-RR lines produce the typical small white seeds of the navy class of dry beans with type II growth habit. The erect, habit (Centro International de Agricultural Tropical classification; van Schoonhoven and Pastor-CotTales, 1987) are desirable characteristics for improved yield and harvest efficiency that have recently been introduced into navybeans. 'C-20','Mayflower', and 'Norstar' navy beans, parents of the BelMiDak lines, were among the first type II navy bean cultivars to be released (Grafton et al., 1993; Kelly et al., 1984, 1989).

Bean rust is an epidemic disease problem in many areas of the world (Stavely and Pastor-Corrales, 1989). Devastating epidemics have occurred in Michigan, North Dakota, and other dry bean production areas of the United States east of the Rocky Mountains (Kelly, 1982; Schwartz, 1984; Venette and Jones, 1982). Many dry bean cultivars are suscep-

Received forpublication21 July 1993. Accepted for publication 28 Dec. 1993. Contribution of Agricultural Research Service, U.S. Dept. of Agriculture, in cooperation with the Michigan and North Dakota Agricultural Expt. Stations. We appreciate bean common mosaic virus indexing by Matt $\mathrm{J}$. Silbernagel, technical assistance from Eugene Frazier, and photographic assistance from James $\mathrm{S}$. Plaskowitz. The cost of publishing this paper was defrayed in part by the payment of page charges. be hereby marked advertisement solely to indicate this fact.

'Research Plant Pathologist.

${ }^{2}$ Associate Professor. narrow profile and short vine type II growth Under postal regulations, this paper therefore must tible to most of the pathogenic races of $U$. appendiculatus in the collection housed at the Molecular Plant Pathology Laboratory in Beltsville, Md. There also are $\geq 15$ races virulent on the few navy and pinto cultivars that are resistant to most of these races (Mmbaga and Stavely, 1988; Stavely, 1984, 1987; Stavely and Batra, 1991; Stavely et al., 1989). Fungicides can be applied to minimize losses, but one of the two major fungicides used for rust control has been under threat of withdrawal and the other is less cost effective.

Uromyces appendiculatus is one of the most pathogenically variable rust fungi. Field collections from bean production areas in North, South, and Central America and Africa, Europe, and Asia have yielded 65 races of the pathogen that have been purified, described, and maintained in liquid nitrogen storage at the Molecular Plant Pathology Laboratory. These races include the only defined races that are virulent on several of the more broadly rust-resistant beans (Mmbaga and Stavely, 1988; Stavely, 1984; Stavely and Batra, 1991; Stavely et al., 1989).

\section{Sources of rust resistance}

PI 181996, the major source of rust resistance in these releases, was among four of 1081 P. vulgaris PIs that showed nonsegregating resistance to all available races of $U$. appendiculatus in 1987 (Stavely, 1988). It has been resistant to all races obtained by the Molecular Plant Pathology Laboratory since then and in all of the other places where it has been tested. Its resistance to most races is expressed as tiny, faint chlorotic spots; 15 races have such spots with tiny, spot-dating uredinia.Thisresistanceis controlled by tightly linked, single dominant genes (Stavely, 1990).

BelMiDak-RR-1, -2, -8, and -9 are homozygous, and BelMiDak-RR-7 is heterogeneous for a second, independent, rust-resistance gene, Up-2 (Christ and Groth, 1982). These lines are the first dry beans to contain the Up-2 gene. It is present in many bush snap bean cultivars, where it causes a distinct, hypersensitive, necrotic spot $\leq 1.0 \mathrm{~mm}$ in diameter and no sporulation with $U$. appendiculatus races $40,44,48-51,54,62-66,69-71,73-76$,
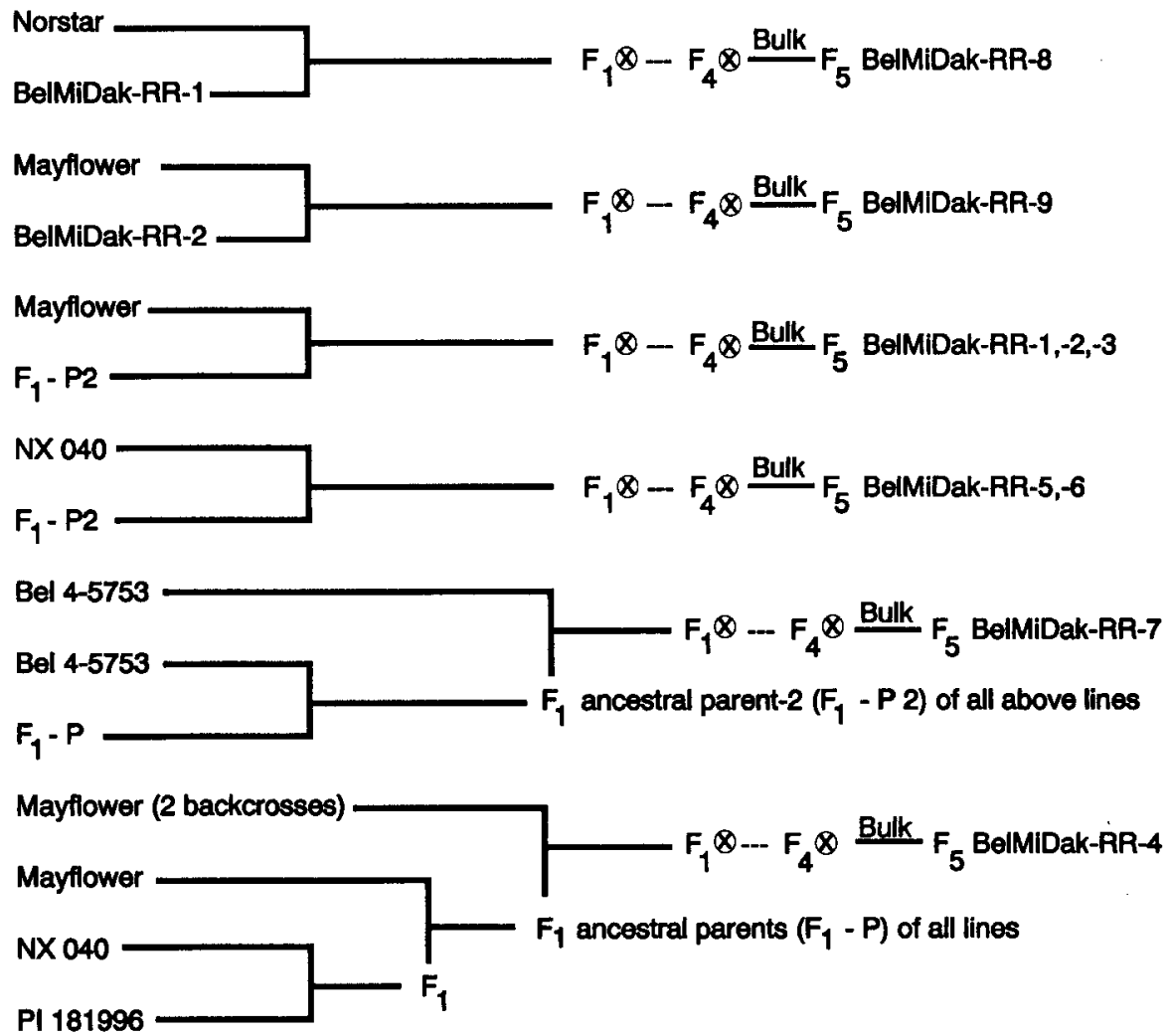

Fig. 1. Pedigree of BelMiDak-Rust-Resistant-1, $-2,-3,-4,-5,-6,-7,-8$, and -9 erect, short vine type II, navy bean germplasm lines. 
$78,81,82,85,86$, and Taiwan-2. The $U p-2$ gene was transferred from 'Early Gallatin' snap bean, through the cross of 'C-20' with 'Early Gallatin' and four backcrosses with 'C20 ' at the Molecular Plant Pathology Laboratory to produce the unreleased line Bel 4-5753. In 1988, Bel 4-5753 was selected for phenotypic similarity to 'C-20' from among 87 related lines in Michigan. When present in plants of the BelMiDak navy lines, this gene has responded to infection from all of the races for which it is effective by forming a tiny, faint chlorotic spot.

To facilitate selection for the Up-2 gene in dry beans, a polymerase chain reaction-random amplified polymorphic DNA (PCRRAPD) marker tightly linked to Up-2 was identified recently using primer OA $141_{1100}$ (Miklas et al., 1993). The PCR-RAPD technique that uses oligonucleotide primer $0 \mathrm{~A} 14_{1100}$ has been used at the Molecular Plant Pathology Laboratory since its discovery to facilitate analysis for Up-2 presence in these BelMiDak lines.

\section{Origin}

BelMiDak-RR-1 through -9 were developed by pedigree and backcross breeding. The objective was to combine resistance to all available races of $U$. appendiculatus into type II growth habit germplasm lines adapted for Michigan and North Dakota. These lines also would have desirable yield, seed, and maturity characteristics for navy dry beans. Additional objectives were to obtain earlier maturity than 'C-20' and 'Mayflower', incorporate the $U p$ 2 rust-resistance gene, and include the $I$ gene for bean common mosaic virus (BCMV) resistance.

Progeny from all crosses, backcrosses, and selfs were selected for rust resistance in each generation after inoculation with eight to 12 keyraces of $U$. appendiculatus (Stavely, 1983). The nine released lines have the same initial pedigree (bottom of Fig. 1). North Dakota navy bean breeding line NX-040, an early maturing sib-line of subsequently released 'Norstar' (typeII), was crossed with PI181996. The resulting $F_{1}$ plants were crossed with 'Mayflower' to produce $F_{1}$ plants that were ancestral parents $\left(\mathrm{F}_{1}-\mathrm{P}\right)$ of all of the lines being released. Navy cultivars or lines were used as female parents in both of these and all subsequent crosses. Across and backcross of 'Mayflower' with $\mathrm{anF}_{1}$-Pplantproduced BelMiDakRR-4. The rest of the BelMiDak lines are descended from a second $\mathrm{F}_{1}$ parental plant $\left(\mathrm{F}_{1}\right.$ $\mathrm{P} 2$ ) derived from crossing Bel 4-5753 with art $\mathrm{F}_{1}-\mathrm{P}$ plant. A backcross of Bel 4-5753 with $\mathrm{F}_{1}-$ $\mathrm{P} 2$ produced BelMiDak-RR-7. A cross of NX040 with $\mathrm{F}_{1}-\mathrm{P} 2$ producedBelMiDak-RR-5 and -6 , and a cross of 'Mayflower' with $\mathrm{F}_{1}-\mathrm{P} 2$ produced BelMiDak-RR-1, -2, and -3. Crosses of 'Norstar' with BelMiDak-RR-1 and of 'Mayflower' with BelMiDak-RR-2 produced BelMiDak-RR-8 and -9, respectively.

After the final cross, progeny were selected for rust resistance and advanced to the $\mathrm{F}_{3}$ generation to identify homozygosity for rust resistance. In 1990 and 1992, $\mathrm{F}_{4}$ progeny rows from each of 366 and 191, respectively, of these homozygous rust-resistant $\mathrm{F}_{3}$ plants were field-planted in East Lansing ( 1990) and Saginaw (1992), Mich., in mid-June. In 1990 and 1992, $F_{4}$ progeny rows from each of 289 and 214, respectively, were field-planted in late May in Barrington (1990) and Arthur (1992), N.D. The lines were evaluated for horticultural-agronotic characteristics and rust resistance in August and September in both states. The released lines have been evaluated for horticultural-agronomic characteristics and rust resistance in Maryland, Michigan, and North Dakota in one or more years since their initial selection.

\section{Description}

Resistance of the BelMiDak lines to the 65 races of $U$. appendiculatus maintained and tested on the lines at the Molecular Plant Pathology Laboratory is generally similar to that of PI 181996 (Stavely, 1988, 1990; J. R. S., unpublished). However, in these navy bean lines, infection with some races advances slightly beyond the stage reached inPI181996. For 12 of the races, the chlorotic spot reaction of PI 181996 develops to the tiny uredinium stage (Fig. 2), which is still a visible and effective resistant reaction (Stavely and Pastor-Corrales, 1989). PCR-RAPD analysis with primerOA $14_{1100}$ revealedthatBelMiDak-RR$1,-2,-8,-9$, and some plants of BelMiDakRR-7 carry $U p$ - 2, but BelMiDak-RR-3, -4,-5, and -6 do not. The presence of $U p-2$ was also evaluated in $\mathrm{F}_{2}$ populations from crosses of the BelMiDak lines with rust-susceptible cultivars. Segregation for the pertinent races in populations of $\geq 70$ plants fit one of two ratios: 12 tiny, faint chlorotic spots :3 distinct necrotic spots $\geq 1.0 \mathrm{~mm}$ in diameter : 1 large, susceptible-type uredinia (when $U p$ - 2 was present) or 3 necrotic or faint chlorotic spots or tiny uredinia $<0.3 \mathrm{~mm}$ in diameter :1 large, susceptible-type uredinia (when $U p-2$ was absent).

We also found that the presence of $U p-2$ with PI 181996 resistance inhibits infection by those races against which it is effective, so that only the tiny, faint chlorotic reaction and no uredinia are produced. Thus, navy bean plants containing $U p-2$ and the independent resistance from PI 181996 limit infections by races $44,50,62,64,66,73,78,85$, and 86 more than infection is limited in PI 181996 without $U p$ 2 , in which these races produce tiny uredinia (Fig. 2). Lines BelMiDak-RR-5 through-9 are homozygous for the $\mathrm{Z}$ gene for resistance to $\mathrm{BCMV}$, and line -3 is heterogeneous for it. Lines -8 and -9 were the first lines to be released that contained homozygosity for the PI 181996 linkage group of the rust resistance genes, $U p-2$, and $I$. Lines- 8 and- 9 also contain a recessive gene for BCMV resistance, either $b c-1$ or $b c-1^{2}$, that is homozygousin line -8 and heterogeneous in line -9 . The $b c-1$ or $b c-12$ alleles provide partial protection of $\mathrm{Z}$ against necrotic strains of BCMV.

The plant and seed traits of all nine BelMiDak-RR lines were within the range for type II navy beans when compared with 'Mayflower' and 'Norstar' in Maryland and Michigan in 1992 and 1993. Plant heights, from the base of the plant to the highest pod, were taller than 'Norstar' (average $37 \mathrm{~cm}$ ), with BelMiDak-RR-4 and -5 being the tallest (average $50 \mathrm{~cm}$ ). All nine lines were similar to 'Mayflower' in plant erectness and had their pods well distributed up the plant. The pods of all nine lines were attached higher on the plant than on 'Norstar', but the pods on BelMiDalcRR-9 were attached lower than on the other lines. Also, BelMiDak-RR-9 consistently had the earliest maturity, which was comparable to

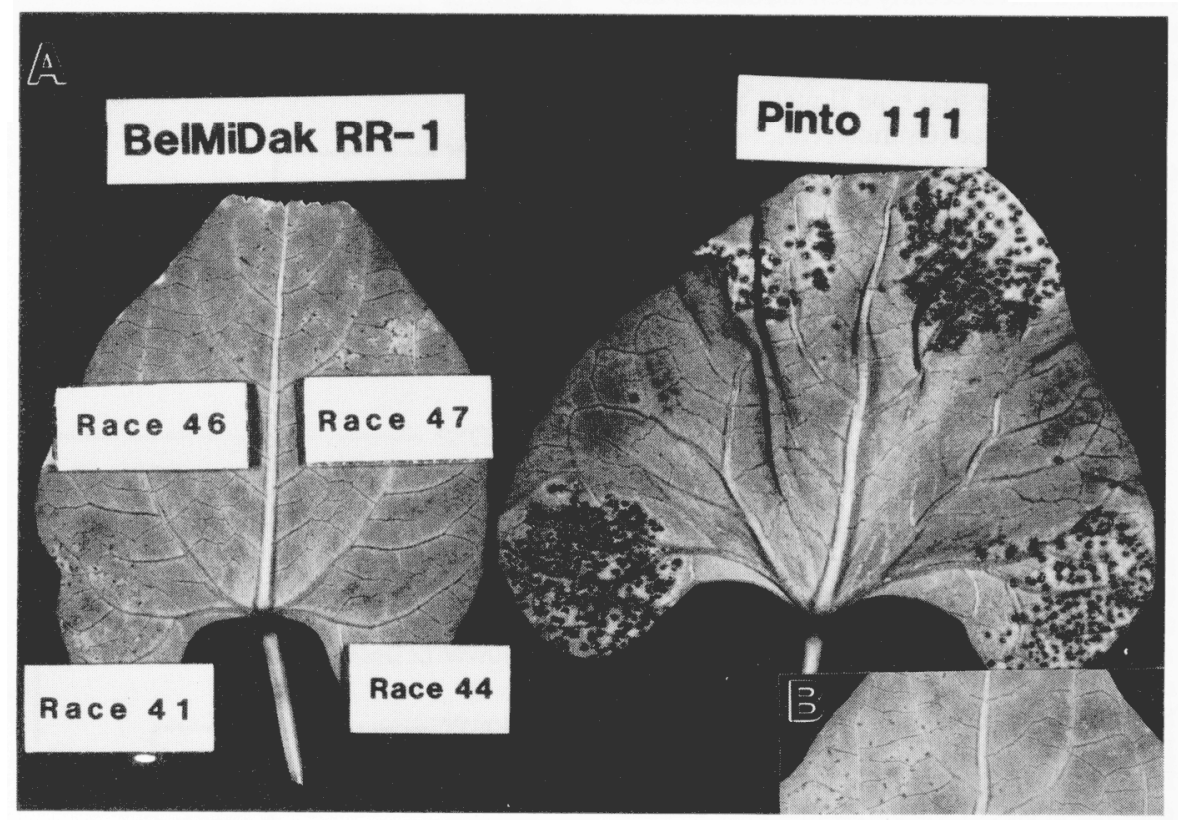

Fig. 2. Reactions of navy dry bean germplasm line BelMiDak-Rust-Resistant-1 and rust-susceptible dry bean cultivar Pinto 111 to the bean rust fungus Uromyces appendiculatus. (A) Clockwise from bottom left on each leaf are $U$. appendiculatus races $41,46,47$, and 44 . (B) Tiny uredinium reaction to race 58 and faint chlorotic reaction to race 67 of BelMiDak-Rust-Resistant-1. 
that of 'Norstar' and $\approx 5$ days earlier than that of 'Mayflower'. The other released lines matured at the same time (BelMiDak-RR-1) or $\leq 3$ days earlier (BelMiDa-RR-4and-7) than 'Mayflower'. Average seed weights over 2 years varied from 17.0 (BelMiDak-RR-1) to 23.8 (BelMiDak-RR-7) g/100 seeds. BelMiDakRR-1 consistently had the smallest and BelMiDalc-RR-7 consistently had the largest seeds. Seeds of 'Mayflower' and 'Norstar' averaged 19.4 and $17.7 \mathrm{~g} / 100$, respectively. The seeds of $-1,-2,-8$, and -9 were nearly spherical like those of 'Norstar', and those of the other lines were slightly oval like those of 'Mayflower'.

\section{Availability}

A limited quantity of seed of BelMiDakRR- I through -9 is available from J.R.S.

\section{Literature Cited}

Christ, B.J. and J.V. Groth. 1982. Inheritance of resistancein three cultivars of beans to the bean rust pathogen and the interaction of virulence and resistance genes. Phytopathology 72:771773.

Grafton, K. F., K.C. Chang, J.R. Venette, and A.J.
VanderWal.1993. Registration of Norstarnavy bean. Crop Sci. 33:1405-1406.

Kelly, J.D. 1982. Varietat and class diversity and accentuation of bean disease problems in a major production area. Proc. Bean Improvement Coop. and Natl. Dry Bean Council Res. Conf., Univ. of Florida, Gainesville, 5-7 Jan. 1982. p. 12-14.

Kelly, J.D., M.W. Adams, A.W. Saettler, G.L. Hostield, and A. Ghaderi. 1984. Registration of C-20 navy bean. Crop Sci. 24:822.

Kelly, J.D., M.W. Adams, A.W. Saettler, G.L. Hosfield, G.V. Varner, J.S. Beaver, M.A. Uebersax, and J. Taylor. 1989. Registration of Mayflowernavybean.Crop Sci. 29:1571-1572.

Miktas, P.N., J.R. Stavely, and J.D. Kelly. 1993. Identification and potential use of a molecular marker for rust resistance in common bean. Theor. Appl. Genet. 85:745-749.

Mmbaga, M.T. and J.R. Stavely. 1988. Pathogenic variability in Uromyces appendiculatus from Tanzania and rust resistance in Tanzanian bean cultivars Plant Dis. 72:259-262.

Schwartz, H.F. 1984. Dry bean disease managementstrategiesinColorado.BeanImprovement Coop. Annu. Rpt. 27:6.

Stavely, J.R. 1983. A rapid technique for inoculation of Phaseolus vulgaris with multiple pathotypes of Uromyces phaseoli. Phytopathology 73:676-679.

Stavely, .J.R. 1984. Pathogenic specialization in Uromyces phaseoli intheUnited States and rust resistance in beans. Plant Dis. 68:95-99.

Stavely, J.R. 1987. Reaction of navy or small white and pinto Phaseolus vulgaris cultivars to Uromyces appendiculatus. Phytopathology 77:1689.

Stavely, J.R. 1988. Occurrence of rust resistance in Phaseolus plant introductions 90658 through 194331: Bean Improvement Coop. Annu. Rpt. 31:128-129.

Stavely, J.R. 1990. Genetics of rust resistance in Phaseolus vulgaris plant introduction 181996. Phytopathology80:1056.(Abstr.)

Stavely,J.R. and L.R. Batra. 1991. Recently identified new pathogenic variability in Uromyces appendiculatus. Phytopathology81:704.

Stavely,J.R.andM.A. Pastor-Corrales. 1989. Rust, p.159-194. In: H.F. Schwartz and M.A. PastorCorrales (eds.). Bean production problems in thetropics.CentroIntemacional de Agricultura Tropical,Cali, Colombia.

Stavely,J.R.,J.R.Steadman,andR.T. McMillan, Jr. 1989. New pathogenic variability in Uromyces appendiculatus in North America. Plant Dis. 73:428-432.

Venette, J.R. and D.A. Jones. 1982. Yield losses associatedwithseventy of bean rust ( Uromyces phaseoli) on pinto beans (Phaseolus vulgaris UI-114). Phytopathology 72:974.

van Schoonhoven, A. and M.A. Pastor-Corrales. 1987. Standard system for the evaluation of bean germplasm. Centro International de AgriculturalTropical,Cali,Colombia. 